\title{
The Application of Discarded Instruments in the Teaching of Agricultural Analytical Instruments for Improving the Comprehensive Ability of Students
}

\author{
Yang Renjie * (Corresponding Author) \\ College of Engineering and Technology \\ Tianjin Agricultural University \\ Tianjin, China \\ rjyang1978@163.com \\ Yang Yanrong \\ College of Engineering and Technology \\ Tianjin Agricultural University \\ Tianjin, China \\ 1605471320@qq.com
}

\author{
Du Yanhong \\ College of Engineering and Technology \\ Tianjin Agricultural University \\ Tianjin, China \\ 19776289@qq.com \\ Dong Guimei \\ College of Engineering and Technology \\ Tianjin Agricultural University \\ Tianjin, China \\ 32568403@qq.com
}

\begin{abstract}
The results of many teaching researches show that the filling teaching mode in old teaching system has seriously restricted the cultivation of students' comprehensive ability. It is imperative to set up a new teaching mode of taking students as the main body. The application of discarded instruments in the teaching of agricultural analytical instruments to train students' comprehensive abilities was proposed in this paper under the environment of advocating a conservation-oriented society. In the experimental teaching of disassembly and assembly, the students can independently put forward the experimental subject, the experimental equipment and the experiment content in terms of their own ideas, and write the principle and procedure of the experiment. The initiative of students' learning has been mobilized by the combination of their own knowledge and personal interests, so that students truly become the masters of the classroom. The disassembly, maintenance and assembly of the discarded instruments can not only make the students' creativity fully, but also enhance their ability of analyzing and solving problems.
\end{abstract}

Keywords-Discarded Instruments, Teaching Methods, Agriculture Analytical Instruments Course, Students, Disassembly Experiments, Comprehensive ability Training

\section{INTRODUCTION}

College students are the main force of modernization in twentyfirst Century. Society needs innovative talents with high quality. The implementation of quality education should focus on cultivating students' innovative spirit and practical ability. As an engineering department of the agricultural college, most of the graduates go to work directly after graduation. The work position requires graduates to have a certain degree of innovation and creativity as well as the spirit of unity and cooperation. How to train them into high quality innovative talents is an important task to be studied and solved.

Higher education should focus on cultivating innovative ability,

1. Education Reform and Innovation Development Funds of Tianjin Agricultural University (20170202).

2. Innovation and entrepreneurship training reform model projects of Tianjin Agricultural University (20170812). practical ability and entrepreneurial spirit. Innovation ability has become the primary ability of college students. Therefore, how to cultivate students' innovation ability has been studyed by many teachers. Wu Jian set up an innovation laboratory on the basis the discarded instruments. Some practices and precautions in the course of disassembly and assembly experiment teaching were studied. It is pointed out that the disassembly and assembly of discarded instruments can effectively cultivate students' comprehensive quality [1]. Ceng Huifang et al used discarded instruments for experimental teaching, and pointed out that this method not only made use of the discarded instruments, but also improved the students' innovation ability [2]. Zhang Jianqiu established a comprehensive and open laboratory using waste equipment, and pointed out that this method not only could save the resources for the school, but also could cultivate the creative talents for the society [3]. Chen Cai et al. built an innovative practical platform for students using scrapped experimental equipment. It is pointed out that this method enables students not only to understand the principle and procedure of the experiment, improve their ability, but also to realize the waste utilization and cost savings [4].

In this paper, the teaching method of application of discarding instrument was put forward in the course of theory and experiment teaching. The proposed method can not only cultivate students' ability of practice, theory and practice ability, innovation ability, but also can make use of discarded equipment resources to be reused and save cost. This study provides a new teaching idea and method for related majors.

\section{INITIATIVE OF CURRICULUM-AGRICULTURE ANALYTICAL INSTRUMENT}

Tianjin Agricultural University Institute of engineering and technology has set up a series of testing and control of professional courses in accordance with the needs of enterprises and professional skills requirements. Agricultural analysis instrument is an important professional course. Agricultural analytical instrument, which is a practical and applied discipline, is a major course in agricultural 
colleges and universities. This course is essentially different from the course of instrumental analysis. Agricultural analysis instrument emphasizes the teaching of hardware teaching, and instrumental analysis emphasizes the teaching of analytical methods. The course of agricultural analytical instrument was firstly set up in Tianjin Agricultural University Institute of engineering and technology. Other agricultural colleges and universities did not set up this course in the country. In order to make students from the perceptual and rational grasp of agricultural knowledge analysis instrument principle and structure, to help them make better use of the instrument in the future, students need to operate the instruments themselves and do a series of experiments. The relevant experimental instruments should be provided. However, regardless of the view from the funds, or instrument management perspective, the purchase of these instruments is unrealistic. Therefore, it is very important to train students' ability to by carrying out the disassembly, mapping, and maintenance of the discarded instruments.

\section{IMPROVING TEACHING EFFECT THROUGH DISCARDED INSTRUMENTS}

\section{A. Theory teaching}

With the expansion of Tianjin Agricultural University, a large number of damaged, obsolete, and low precision instruments have been scrapped every year. These scrapped instruments are often discarded. From the point of view of assets, it is a waste of resources. How to make full use of these discarded instruments train more and more qualified talents for the society. The discarded instrument is used in the theoretical and experimental teaching of agricultural analytical instrument, which can solve the above two problems at the same time. The teaching of agricultural analytical instrument focuses on the cultivation and improvement of students' skill, ability and quality.

At present, there are a lot of instrumental analysis textbooks, and agricultural analytical instruments textbooks are few. Therefore, our professional teaching and research group has carried out the program of agricultural analytical instruments textbook, which can not only meet the needs of our own teaching, but also meet the needs of other agricultural colleges and universities.

On the basis of the a discarded instruments, in the course of the teaching of the theory of agricultural analytical instruments, the corresponding components are disassembled and explained in terms of the contents of the teaching. Therefore, students can figuratively understand and master the principle and structure of the analytical instruments. The teaching method overcomes the problems of the previous teaching, which is difficult to be understood by the teachers, or the students are not interested in the theoretical explanation. The following example will be used to further illustrate. The teacher disassembled the grating from the discarded spectrum instrument. The object of grating was used in the teaching of the theory of agricultural analytical instruments. The teacher can not only explain the composition, structure and the related principle of the grating directly to the students, but also through the demonstration experiment, so that the students can observe the imaging phenomenon of the grating directly. This teaching method can not only improve the students' interest in learning, but also make it easier for students to understand and master the content.

\section{B. Experiment teaching}

The cultivation of students' comprehensive ability runs through all aspects of teaching. The most important and effective way is to emphasize and strengthen the experiment teaching. Experimental teaching is an important way for students to acquire knowledge and ability, and it is also an important part of innovation education. Experimental teaching plays an irreplaceable role in the cultivation of innovative talents. Therefore, the discarded instruments are used in the experiment teaching on the basis of the above theoretical teaching. For the discarded instruments, students can carry out disassembly, mapping, maintenance and assembly to improve their abilities [5].

As an important part of the teaching reform, the disassembly and assembly experiment is very different from the traditional experimental teaching. The disassembly and assembly experiment disassembly and mapping experiment is an organic combination of knowledge, skills and creative thinking ability. The experimental teaching needs to do the work in the following stage: the mobilization stage, selection module stage, preparation stage, teachers lecture stage, disassembly and mapping stage, assembly and maintenance stage, and assessment stage (Fig.1).

Mobilization stage needs to do the following work:explaining the meaning, purpose and requirement of the disassembly analysis instrument; explaining the basic methods and essentials of disassembly analysis instrument; explaining precautions and grouping.

Selection module stage needs to do the following work:choosing 2-3 modules from 8 modules for disassembly, mapping, maintenance and assembly. According to the selected module, students receive the discarded instruments for experiment.

Preparation stage needs to do the following work:Setting a range of thinking for students and preparing relevant knowledge. Due to the limited number of discarded instruments, so students should be targeted to avoid dismounting and boundless. Therefore, it is very necessary for students to understand the general situation of the discarded equipment. Teachers provide students with some simple and practical technical information, technical information, patent related instrument manual for students to read, and to help students review and review some relevant knowledge, guide the students to prepare and pre experiment knowledge.

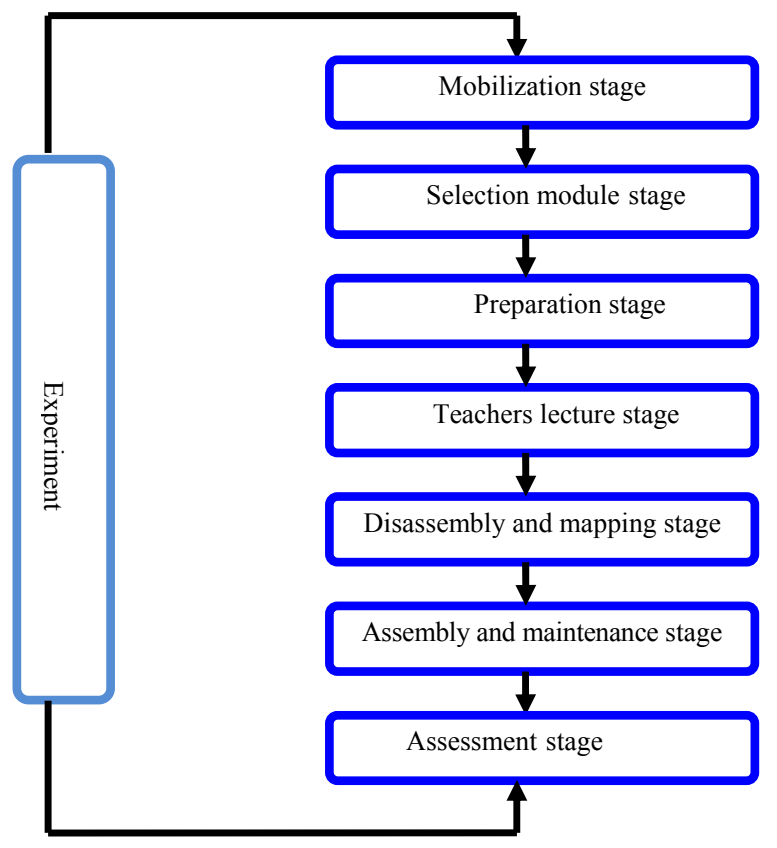

Fig. 1. The six stages of experimental teaching 
Teachers lecture stage needs to do the following work:teaching knowledge of disassembly and assembly experiment for students. 810 Lectures were generally opened, including hardware, software and circuit design. According to the students choose the type of disassembly and assembly instrument, the teachers introduce the relevant knowledge of the instrument - working principle and structure, as well as the composition of the various parts of disassembly, mapping, maintenance and assembly.

The stages of disassembly and mapping, assembly and maintenance are the two most important stages in the whole experiment. The stage of disassembly and mapping is mainly to disassemble the discarded instruments, and to map the components or devices. The stage of assembly and maintenance is to carry out the organic combination of knowledge and object to complete the debugging and maintenance of the instrument. These two stages are the most able to reflect and improve the students' ability of creative thinking and practical ability, but also the most problematic, the most need of teachers and laboratory personnel to provide guidance and help stage. Therefore, we should give full attention to and strengthen the timely guidance of inspections.

\section{1) Assessment of the ability to use knowledge}

The number of knowledge points reflected in the final experiment report can reflect the level of application ability. Therefore, students should be as much as possible in the experimental report to reflect the application of the knowledge points, to enable the students to study for the application.

\section{2) Assessment of operation}

Firstly, the teachers in the experimental process can strengthen assessment of operation through checking the proficiency of the students. Secondly, the assessment of operation can strengthen through checking the number of using the tools, components, raw materials; the production of auxiliary mappings (such as circuit diagrams, assembly mappings), etc. Finally, the assessment can strengthen directly to the operation of students.

\section{3) Assessment of expression ability}

The expression ability mainly refers to the summary narration and expression of the experimental report, including two aspects: oral and written expression. Disassembly and assembly experiments report could not get from any textbooks, students must map, abstract and summary instruments so as to form the report, therefore, this is one of the key steps in the training of students' comprehensive ability. The principle of the instrument can reflect the students' understanding of the structure and use of the instrument. The mapping of each component and control technology can reflect the rigor of the students' logical thinking. The form of oral expression is evaluated as a unit, the group leader introduces the progress of the group and the division of labor among the members, and the members of the group respectively describe the work done by self and carry out the assessment. In the process of students' narrative, we can also understand the students' active participation and the cooperation of the students.

\section{4) Assessment of experimental reports}

This part of the students should be assessed in the use of theoretical knowledge, mapping the structure of the actual mapping circuit and wiring diagram, and the correctness of the conclusions in the course of the experiment.

\section{IMPROVING COMPREHENSION ABILITY OF STUDENTS THROUGH DISCARDED INSTRUMENTS}

Disassembly and assembly experiment can be truly student oriented, supplemented by teachers. In general, in order to achieve the goal of teaching, teachers usually set up a lot of rules for students and then let the students do it step by step. This not only makes the students lose the initiative of learning, but also deprives the students of creativity in the experiment. In the disassembly experiment, students are faced with waste equipment, curiosity and the interests of the equipment; they will produce a variety of ideas, which are motivated to stimulate a variety of learning. Motivated by these learning motivations, students will not only actively use the existing knowledge, but also actively learn new knowledge and are willing to get help from teachers. Therefore, in the disassembly experiment, students become the leading role, and the teachers become the tutor role. The conversion of roles is just the need of ability training. The disassembly and assembly experiments can cultivate students' comprehensive ability. After the experiment, the ability of the students is investigated, and the results are given in Fig. 2.

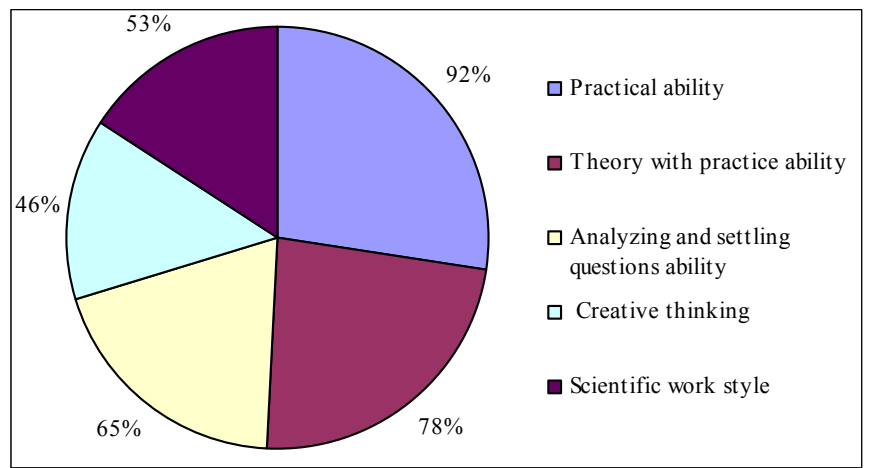

Fig. 2. The statistical analysis of training student's abilities in disassembly and assembly experiment

(1) Improving students' practical ability. The experiment is carried out on the basis of the scrapped instrument, so that students can boldly dismantle, install, repair, and create, so as to improve students' practical ability.

(2) Training of student's theory with practice ability. Because the disassembly and assembly of an instrument will involve a number of courses related theoretical knowledge. Through disassembly and consolidation, the consolidation of the knowledge learned on the textbook, the more important is to link the theory and knowledge.

(3) Improving student's ability on putting forward, analyzing and settling questions. Students should encounter many problems in the process of mapping, debugging and maintenance equipment. For example: if the instrument is not working properly, students firstly need to understand where the problem of a device, to detect problems found by other tools. It is necessary to analyze the cause of the problem, and come up with a solution.

(4) Cultivating and developing students' creative thinking. Compared with the previous experiment, the biggest difference is that disassembly and assembly experiments can provide the students with the most creative space. For discarded equipments, students can not only disassemble the equipments, but also map various components, understand the principle, carries on the maintenance or based on their grasp of existing knowledge and equipment for scrap recycling value to improve the degree of recognition, which greatly stimulated the students' curiosity and learning motivation. In addition, the 
disassembly experiment can also play a very good role in cultivating and developing the students' scattered thinking and intuitive thinking.

(5) Training students' rigorous scientific work style. Disassembly of the instruments is not a simple or random removal of the various parts of the instruments. The instruments need to be reassembled after dismantling, mapping debugging maintenance. Therefore, students are required to disassemble the instrument in the process of mapping instrument assembly, parts assembly, and components are effectively combined, and establish a good work style.

\section{CONCLUSIONS}

In this paper, on the basis of discarded instruments, students are allowed to disassemble, mapping and analyze the discarded instruments. The teaching method not only meets the needs of the experiment, but also develops the students' comprehensive ability. The teaching method can help students to integrate the contents of various professional courses, train and improve students' ability of using the theoretical knowledge, operating and debugging hardware design, designing of optical electromechanical integration, analyzing system characteristic, solving engineering problems. Through the training of the above abilities, these students have won many awards in the national innovation competition, and received the unanimous praise of educational experts. In a word, the use of discard equipment for agricultural analysis instrument teaching not only greatly improve the students' ability in all aspects, for students to lay the foundation for future work, but also solve the school's worries of dealing with discarded equipment.

\section{ACKNOWLEDGEMENT}

This work was financially supported by the Education Reform and Innovation Development Funds of Tianjin Agricultural University (20170202), and innovation and entrepreneurship training reform model projects of Tianjin Agricultural University (20170812).

\section{REFERENCES}

[1] Wu Jian. Turing to account of the scrap apparatus to improve the general capabilities of students [J]. Journal of Liaoning Institute of Science And Technology, 2006, 8(1):71-73.(In Chinese)

[2] Zeng Huifang, Xiao Suigui. Reuse of waste instruments and equipment and the cultivation of practical innovation ability [J]. Journal of Yichun University (natural science), 2003, 25(2):122-123.(In Chinese)

[3] Zhang Jianqiu. Make use of waste instruments to build up a comprehensive public laboratory [J]. China Science And Technology Information, 2007, 24:304. (In Chinese)

[4] Chen Can, Li Lin, Liu Fuyu, Ren Xuhu. Effectively using scrapped experiment to provide innovative practical platform for students [J]. Experimental Technology and Management, 2016, 33(11) : 37-40.(In Chinese)

[5] Lin Xingtao, Wang Xiaoyi, Ke Huiming, et al. Exploration and practice of opening experimental teaching by using large instruments and cultivating students' innovative abilities [J]. Experimental Technology and Management, 2013, 30(5): 117-119. (In Chinese) 